\title{
Guest Editorial: Valuing Tourism
}

\author{
Carina Ren, Morten Krogh Petersen and Dianne Dredge
}

\section{Bifurcated Values in Tourism Research}

Why should a reader of this journal care about valuation as social practices in tourism? As special issue editors, we could try to convince you to carry on reading by stipulating that tourism is the world's biggest industry. Statements such as this highlight the worth of tourism in the global marketplace and are reproduced in research papers, reports, conferences, symposia and meetings, from global to local levels. Importance is given to how tourism generates billions of dollars per year in foreign exchange earnings and that it is among the largest of global export industries. Concomitantly, by reproducing this argument about the global economic size and value of tourism, the worthiness of our own tourism-related research within an increasingly competitive research marketplace would also be instantiated. Interestingly, two very different and dominant strands of tourism research-defined here as a managerial approach and a critical approach-take such statements concerning the size of the economic worth generated by tourism as their points of departure.

In the managerial approach to tourism, valuing tourism is seen as a technical matter with a focus on valuing the economic benefits of tourism for the destination. Visitor nights, occupancy rates and expenditure are all measured. Methods and devices such as satellite accounting and cost-benefit analysis are employed to determine

Carina Ren, Department of Culture and Global Studies, Aalborg University Copenhagen,ren@cgs.aau.dk.

Morten Krogh Petersen, Department of Learning and Philosophy, Aalborg University Copenhagen,mkp@learning.aau.dk

Dianne Dredge, Professor, Department of Cultural and Global Studies, Aalborg University Copenhagen,dredge@cgs.aau.dk

(C) 2015 Carina Ren, Morten Krogh Petersen and Dianne Dredge

LiU Electronic Press, DOI 10.3384/VS.2001-5992.153285

http://valuationstudies.liu.se 
foreign and inter-regional exchange earnings, employment generation and investment attraction (e.g. Dwyer and Forsyth 2006). In the last two to three decades this managerial approach has broadened in an attempt to position tourism as much more than an economic activity. The argument here has been that tourism can contribute to sustaining and enhancing social, cultural and environmental goals, sentiments captured by the United Nations World Tourism Organization (UNWTO):

An ever-increasing number of destinations worldwide have opened up to, and invested in tourism, turning it into a key driver of socio-economic progress through the creation of jobs and enterprises, export revenues, and infrastructure development. (UNWTO 2015: 2)

As a result, a wider variety of tools and techniques have emerged to 'get the facts right' by also measuring the social value of tourism. Attempts to measure tourism's impact on the millennium development goals, on poverty alleviation, education, health, welfare and gender empowerment, illustrate this broader view of the value and values of tourism (Bricker et al. 2013).

While approaches to valuing the effects of tourism have undoubtedly allowed for an appreciation of values in tourism beyond the economic, the managerial focus has its limitations. Managerial discussions tend to focus on an overarching solid and singular notion of value, where a blunt economic value (or worth) is pitted against an equally blunt notion of the social or cultural value of tourism. Also, facts as well as values are understood as already 'out-there', ready to be captured and capitalized upon.

One prominent response to this economy-driven approach to 'the world's biggest industry' has been the rise of critical voices from anthropology and cultural studies (MacCannell 1976; Smith 1977) and the emergence of critical tourism studies (e.g. Ateljevic et al. 2007). In this body of research, valuing tourism is concerned with describing the social and cultural implications or impacts of tourism. As with the managerial approach, the starting point is an understanding of tourism as a sizeable economic phenomenon. What differs, however, is that tourism is not seen as a driver for the positive development of social or cultural issues. On the contrary, issues of commodification of local culture have been problematized (Greenwood 1989), and global forces of (economic) power and dominance delineated and chronicled (Urry 1990; Hollinshead 1999; Cheong and Miller 2000). From the earliest attempts at establishing an anthropology of tourism, impacts on the social fabric and local culture were depicted as more or less disastrous (Turner and Ash 1975; Smith 1977; Boissevain 1996). Such studies were often carried out using ethnographic or cultural analytical methods, turning ethnography and qualitative inquiry into the preferred valuing devices. Regularly-if not 
habitually within this critical approach-were these ethnographic and qualitative valuing devices coupled with normative presumptions of authenticity, power and identity and how these were and should (not) be shaped.

Maybe, dear reader, you recognize this branching out of a field of research into two distinct strands from your own field of research? What about food studies? Like tourism, food might be seen as a forceful economic phenomenon that has spurred intellectual interest not only from researchers, but also funding bodies and educational institutions. And perhaps you would not need to dig very deep into the field of food studies before you encounter two strands similar to the ones found within tourism studies, a managerial and a critical approach? An indication that this might be the case is found in Frank Heuts and Annemarie Mol's contribution to an earlier issue of the present journal. In their paper, Heuts and Mol ask: "What is a Good Tomato?" Drawing upon interviews with different tomato actorschefs, growers, gardeners and more-Heuts and Mol answer their question through five registers of valuing, signalling that the question of what is a good tomato is, indeed, a tricky one (Heuts and Mol 2013); perhaps trickier than a field operating with just a managerial or a critical approach can grasp.

Health care studies might constitute a second example. Drawing again on an earlier contribution to the present journal, Teun Zuiderent-Jerak and Stans van Egmond also take a bifurcated field of research as their point of departure in their article 'Ineffable Cultures or Material Devices: What Valuation Studies can Learn from the Disappearance of Ensured Solidarity in a Health Care Market (Zuiderent-Jerak and van Egmond 2015). Zuiderent-Jerak and van Egmond take up the leapfrog debate concerning culture or materiality; which one drives or should drive history? Taking a recent transformation in the Dutch welfare-based health care system from 'fairness' to 'competition' as their empirical case, the two authors "call for a more historical, relational, and dynamic understanding of the role of economists, market devices, and of culture in valuation studies" (Zuiderent-Jerak and van Egmond 2015, 45). Other recent examples of reshuffling value positions can be drawn from fields such as innovation studies (Hyysalo et al. 2016) and taxation studies (Boll 2014).

We suggest that the attention to valuation as a social practice championed by this journal may aid us in tending to such reshufflings. Let us leave food studies, health care studies and other fields behind and discuss how the bringing together of valuation studies and the field of tourism studies might help us go beyond the managerial and the critical approach. Through an empirical example we will also discuss why this may be especially pertinent today. 


\section{Entanglement of Tourism and Valuation}

As we have shown above, the managerial and the critical approaches to tourism are very different in terms of the valuing devices employed, and subsequently in how tourism as a phenomenon is studied and assessed. However, and importantly, the two approaches share an understanding of the values of tourism as relatively stable entities and as being independent from attempts made at measuring or describing them. While the managerial approach assumes that such relatively stable and independent value and values can be measured and, subsequently, furthered, the critical approach assumes that they can be described and, subsequently, critically addressed. Whereas the two predominant strands seem to work from rather clear-cut distinctions between 'the economic' and 'the cultural', between 'the technical' and 'the social', and between 'hard numbers' and 'soft values', much work in the area of valuation studies is marked by cultivating a more agnostic and performative approach (Callon 1986) to questions of valuing and values.

In this approach, values are not understood as determining valuation but are rather the effects of specific and situated valuing practices and devices. It questions our departure point in 'tourism as the world's largest industry', seeing such a claim as an effect of specific and situated valuing practices (see also Latour 2013). To bring tourism research into conversation with the field of valuation studies destabilizes and blurs distinctions between managerial and critical tourism research (see also Ren et al. 2010). It might also lead us to sorting attachments (Jensen 2007) in new ways.

With an attention to valuation as a practice, tourism value and values are seen as the effects or achievements of-rather than reasons for-concrete and situated tourism practices. While statements of tourism size and worth might serve well as political and academic window dressing, we could instead follow the intentions of the current journal, and engage in valuing tourism as a social practice (Helgesson and Muniesa 2013; Kjellberg et al. 2013). Such an approach offers an opportunity to simultaneously unpack what we understand by 'tourism' (Jóhanneson et al. 2015) and to tend to its value and values beyond its being the world's biggest industry. We might, in other words, engage with the "goodnesses" (Mol 2002, 166)-and badnesses, one might add-of tourism in a far more nuanced manner.

To do so-to attend to the goodnesses and badnesses of tourism more carefully-seems timely, as tourism seems to become ever more entangled. To an increasing degree, tourism is managed and performed in ways that are not separate from, but that connect with, a jumble of everyday practices and concerns (Cartier and Lew 2005). This implies that the value and values of tourism turn into something which never stands alone, but is always negotiated in relation to and co-enacted along with other elements and concerns. In that way tourism may be 
said to exemplify what Boltanski and Esquerre have termed 'the economy of enrichment' (Boltanski and Esquerre 2015). Increasingly, tourism is valued by being connected to actors and elements we would not traditionally think of as belonging to the sphere of 'tourism proper' (see also Jóhanneson et al. 2015). As we become increasingly aware that tourism is more complex and entangled than previously assumed, we need to address how its effects are more intensively distributed in, for instance, regional development, city planning, education, innovation and cultural imaginaries, or-as we tend to in the present-in everyday practices. Through the complex linking of many different actors and elements we wish to look into new ways to describe, understand and interfere with the ways in which tourism comes into being and comes to matter.

To illustrate these points concerning the entanglement of tourism and how this calls for a closer collaboration between tourism studies and valuation studies, let us offer an example of how values connect to 'the social' in the everyday life practices of tourism drawing on insights from ongoing research in Greenland.

\section{Towards the Study of New Value Tensions}

In March 2016, Nuuk, the capital city of Greenland, will be hosting the Arctic Winter Games (AWG), the largest event in the island's history. During the event week, the streets of the city of 17,000 inhabitants will be swarming with 2200 young performers and cultural representatives, as well as spectators and journalists from around and beyond the participating circumpolar continents. To prepare for this event, a secretariat was created in 2014, financed by the Greenlandic home rule and the local municipality of Nuuk. Their work has consisted in planning the event, joining together sponsors, partners and the necessary 1500 volunteers to enable the hopefully smooth running of this event. Leading up to the event, the national airline will be gathering its air vessels to transport the thousands of participants and guests under difficult Arctic conditions. City schools will be closed down to lodge the many visitors, and the kitchens of catering businesses will be running full steam to feed them.

AWG illustrates how tourism enters everyday life in a number of powerful ways. Not only when the AWG actually takes place but through the year-long process of planning the event. During that time, connections are forged and requirements are articulated through collaborative efforts of the event actors. Through collaborations with and between civic organizations, educational institutions, the art and music scene and others, new social and public-private configurations are enacted such as citizens-as-volunteers, NGOs-as-partners and companies-as-sponsors. The question is how to make sense of and 
value these emerging realities, which are no longer confined to being singularly about events or tourism?

Here we turn to a paper entitled 'Matter-ing: Or How Might STS Contribute' (2004) by sociologist John Law. In the paper, which explores how the field of Science and Technology Studies (STS) performs specific kinds of value and values, Law deploys the notion of 'modes of mattering' as a specific way of "making realities that matter. Handling matters of concern" (Law 2004, 3; see also Latour 2004). One of the helpful points made is that different modes of mattering configure the relationship between facts and values differently. Let us see how this works for our present case. How would a tourism slash valuation studies researcher go about making sense of and valuing the emerging realities of AWG 2016?

Although the AWG event had not yet taken place at the time of writing, voices of concern in political debates and in the media are being raised about the costs and outcomes of this event. Crudely speaking, the questions raised around the AWG are organized around two concerns, or two kingdoms, as proposed in Law (2004): that of facts and that of values. Focusing on the kingdom of facts, the mode of mattering entitled puzzle-solving seeks to find the missing piece in the jigsaw. It asks: What is the missing (technical) fact? What is the fact that is missing since concerns about the costs and outcomes of this event are being raised? This mode of mattering, puzzle-solving, does not engage in discussing the values of AWG, but is merely concerned with facts: what will this cost, what will we gain, is it worth it-and how to measure all of this in the best possible way?

A second mode of mattering, that of critique, is not so interested in the facts. Indeed, facts are taken to be more or less clear. Critique is interested in values. And it states that the present values have gone wrong. To attempt to matter through critique in the case of AWG would then mean to question the political motivations and power issues related to the event. An example is how government investments related to AWG benefits the interests of the capital city over more marginal areas.

The focus on (missing) facts in the case of puzzle-solving, and on values (gone wrong) in the case of critique, correspond with recognizable fault lines between the two dominant research positions of management studies and critical studies (See Tribe et al. 2015) in tourism research as outlined above. We also stressed how newer studies within both the managerial and the critical approach seem to recognize that economic and cultural concerns must somehow be balanced or transcended. We need, in other words, a better overview of things-how economic and cultural concerns relate. This corresponds with the third of Law's modes of mattering, that of balance. What matters within balance is "the making of balance between things that won't add up in a nice convergent way, that refuse to be located within 
a single calculus of either facts or values" (Law 2004, 4, emphasis in the original).

This is a concern of the event secretariat, turning their work into the preferred sites of the researcher attempting to matter through balancing. In their planning work, the project managers and workers are fully aware of the controversial state of the event regarding its potential as a valuation device in itself. As stated by the general manager: How to make the best of this, when it is due to happen anyway? How do we use this as an occasion to do things, which need to be done anyway? Their words display a constant working in and with tensions, a balancing act between raising facts (i.e. how can the secretariat conduct surveys of what the sponsors get out of it?) and of enacting values (i.e. how can the secretariat better connect the event to sports and health issues in schools?). How that balancing act turns out, which values it produces, and how these are assessed as factual accomplishments, remain to be seen.

The three above modes of mattering-puzzle-solving, critique and balance-all speak of absences, Law posits, "the absence of good values for critique; the absence of just the right piece needed to solve the problem in the case of technical puzzle-solving; or the absence of an overall view in the case of balance" (Law 2004, 5). In bringing to the fore such absences, and in pointing to ways in which these absences may be handled or even turned into presences, the researcher can come to matter in ways that are recognizable across various sites, institutions, organizations, etc. But there are other possible modes of mattering.

While the three previous modes of mattering all assume a somewhat stable reality 'out-there', and keep up a commonsensical distinction between facts and values, interference as a fourth mode of mattering "washes away the singularity of the real" (Law 2004, 5) and erases the clear-cut distinction between facts and values. It does so in three steps. It says, first, that realities are done. Second, these realties are non-coherent and, thus, in interference with one another. The third and last step follows from the first two: if we, as researchers, recognize that realities are done differently in different practices, then we can "interfere and make a difference" (Law 2004, 5). This is what Annemarie Mol has termed ontological politics (Mol 1999).

In the case of AWG 2016 then, the question is: how do the researchers come to matter through interference? And how do they become engaged in ontological politics? We are not sure. It may simply be too early to ask such questions. More research is needed. Research, which does not take a straightforward distinction between facts and values as its point of departure, but as a distinction to be explored empirically. How does the distinction between facts and values come into being in the tourism practices studied? And how might we, as researchers, interfere in this continuous performance of the distinction between facts and values? 


\section{Contributions}

Using insights from previous studies about valuation when tending to tourism (and other fields of research as suggested above) enables us to think about how we should and would like to come to matter. The four contributions of this special issue all grapple-in very different ways-with this. They can be read as experiments in how to come to matter through interference as well as through other and more easily recognizable modes of mattering-puzzle-solving, critique and balance. The idea is not to choose between different modes of mattering, but rather to broaden the palette.

In the first contribution, Morten Krogh Petersen and Carina Ren analytically bracket the public understandings of the (lack of) values of the Eurovision Song Contest held in Copenhagen in 2014, which resulted in a huge and scandalous publically financed deficit. Following Mauss (1925 [2011]), Petersen and Ren propose seeing the event not as an activity, which neatly fits with economic and cultural evaluation devices, but rather as a total social phenomenon, or Potlatch. As they show, actors attribute value to the mega-event along different and interfering project logics and thereby seek to enact different sets of values.

In the second contribution, Lauren Wagner starts in well-known empirical terrain for the field of valuation studies, namely the dynamics of markets. More specifically, Wagner sets out to investigate how the right price is found in the Marrakech bazaar. She draws together insights from recent studies on financial markets, and the market devices that help bring these into being in specific ways, with older, primarily anthropological, studies focusing on marketplaces and on the individuals that conduct trade. Wagner aims not to fixate individuals (as seems to be the case in newer studies) or technologies (as seems to be the case in older studies). Instead, she shows how all entities come into being through negotiations of the value of the artworks sold and the ethnonational category of 'Moroccanness'.

In the third article, Vasiliki Baka takes an historical and performative approach to place-making and places-valuing. Accounts and ratings of travel experiences spanning from the diaries and travelogues of the Grand Tour era, to the guest comment cards found at many hotels from the 1990s, and onwards to the user-generated content and algorithmically produced ratings found on TripAdvisor are understood as valuing devices, which partake in the making and the valuing of places. Baka suggests that although earlier valuing devices have evoked place-making in various ways, the rise of UGC (user-generated content) websites has converted the travel experience into a constant negotiation process whereby the value of places and the value of valuing devices are contested.

In the fourth article, Henrik Merkelsen and Rasmus Kjærgaard Rasmussen unpack the organizational effects of nation brand ranking, 
advancing the argument that the flexible nation branding logic offers an almost unlimited potential for producing organizational effects. Using a case study of a recent nation-branding initiative in Denmark, the authors show how the bureaucrats in charge of the nationbranding initiative successfully translated fuzzy political goals into understandable numerical objectives so that they fitted into their existing bureaucratic practice. This translation allowed for bureaucratic expansion as it continuously maintained and reconstructed problems solvable by the initiation of more nation-branding initiatives and more bureaucratic activity.

\section{Concluding Remarks}

In the foregoing, we have proposed that taking an agnostic and performative approach to how value and values are enacted into being and ordered in tourism challenges current managerial preoccupations with, and critical concerns over, the worth of tourism. This take asks us to give up any premature, analytical distinction between managerial and critical perspectives. The distinction is no longer an analytical starting point, but what has to be researched. Its continuous becoming is what we need to describe and understand. As we tend to the dynamic valuing of tourism as it takes place in the everyday micropractices of the tourism marketplace, we are made more aware of how it is reproduced and institutionalized in mundane or strategic activities.

These insights call for new registers to be developed by which we can describe, understand and interfere with the ways in which tourism comes into being through the complex linking of many different actors. This can be done, we argue, by minutely tracing how tourism is made to matter in different contexts, according to different registers in multiple and often opposing ways. Here the emerging field of valuation studies provides a new lens to explore and understand the social practices of valuation in tourism; and by making these valuing practices explicit, we also make them more open and accountable to scrutiny (Doganova et al. 2014). We hope that this issue will pave the way for many more attempts to tend to tourism values and valuation.

Acknowledgements. As special issue editors, we would like to thank the contributors and the anonymous reviewers for their engagement and swift execution. Also, we would like to thank co-editor-in-chief, Claes-Fredrik Helgesson, for invaluable (!) editorial support throughout. 


\section{References}

Ateljevic, Irena, Annette Pritchard, and Nigel Morgan, eds. 2007. The Critical Turn in Tourism Studies. Oxford: Elsevier.

Boissevain, Jeremy, ed. 1996. Coping with Tourists: European Reactions to Mass Tourism. Oxford: Berghahn Books.

Boll, Karen. 2014. "Mapping Tax Compliance: Assemblages, Distributed Action and Practices: A New Way of Doing Tax Research." Critical Perspectives on Accounting 25 (4): 293-303.

Boltanski, Luc, and Arnaud Esquerre. 2015. "Grappling with the Economy of Enrichment." Valuation Studies 3 (1): 75-83.

Bricker, Kelly, Rosemary Black, and Stuart Cottrell. 2013. Sustainable Tourism and the Millennium Development Goals: Effecting Positive Change. Burlington, MA: Jones and Bartlett.

Callon, Michel. 1986. "Some Elements of a Sociology of Translation: Domestication of the Scallops and the Fishermen of St Brieuc Bay." In Power, Action, and Belief: A New Sociology of Knowledge, edited by John Law, 196-223. London and Boston, MA: Routledge and Kegan Paul.

Cartier, Carolyn, and Alan A. Lew, eds. 2005. Seductions of Place: Geographical Perspectives on Globalization and Touristed Landscapes. London: Routledge.

Cheong, So-Min, and Marc L. Miller 2000. "Power and Tourism: A Foucauldian Observation.” Annals of Tourism Research 27 (2): 371-390.

Doganova, Liliana, Martin Giraudeau, Claes-Fredrik Helgesson, Hans Kjellberg, Francis Lee, Alexandre Mallard, Andrea Mennicken, Fabian Muniesa, Ebba Sjögren, and Teun Zuiderent-Jerak. 2014. "Editorial Note: Valuation Studies and the Critique of Valuation." Valuation Studies 2 (2): 87-96.

Dwyer, Larry, and Peter Forsyth. 2006. International Handbook on Tourism Economics. New York: Edward Elgar.

Greenwood, Davydd. 1989. "Culture by the Pound: An Anthropological Perspective on Tourism as Cultural Commoditization." In Hosts and Guests. The Anthropology of Tourism, 2nd ed., edited by Valene Smith, 171-185. Philadelphia, PA: University of Pennsylvania Press.

Helgesson, Claes-Fredrik, and Fabian Muniesa. 2013. "For What it's Worth: An Introduction to Valuation Studies." Valuation Studies 1 (1): 1-10.

Heuts, Frank, and Annemarie Mol. 2013. "What is a Good Tomato? A Case of Valuing in Practice." Valuation Studies 1 (2): 125-146.

Hollinshead, Keith. 1999. "Surveillance of the Worlds of Tourism: Foucault and the Eye-Of-Power." Tourism Management 20 (1): 7-23.

Hyysalo, Sampsa, Torben Elgaard Jensen, and Nelly Oudshoorn, eds. 2016. The New Production of Users: Changing Innovation Collectives and Involvement Strategies. New York: Routledge.

Jensen, Casper Bruun. 2007. "Sorting Attachments: Usefulness of STS in Healthcare Practice and Policy." Science as Culture 16 (3): 237-251. 
Jóhannesson, Gunnar, Carina Ren, and René van der Duim, eds. 2015. Tourism Encounters and Controversies: Ontological Politics of Tourism Development. Farnham and Burlington, VT: Ashgate.

Kjellberg, Hans, Alexandre Mallard, Diane-Laure Arjaliès, Patrick Aspers, Stefan Beljean, Alexandra Bidet, Alerberto Corsin, Emmanuel Didier, Marion Fourcade, Susi Geiger, Klaus Hoeyer, Michèle Lamont, Donald MacKenzie, Bill Maurer, Jan Mouritsen, Ebba Sjögren, Kjell Tryggestad, François Vatin, and Steve Woolgar. 2013. "Valuation Studies? Our Collective Two Cents." Valuation Studies 1 (1): 11-30.

Latour, Bruno. 2004. "Why has Critique Run out of Steam? From Matters of Fact to Matters of Concern." Critical Inquiry 30 (2): 225-248.

Latour, Bruno. 2013. "Biography of an Inquiry: On a Book about Modes of Existence." Social Studies of Science 43 (2): 287-301.

Law, John. 2004. “Matter-ing: Or How Might STS Contribute?” Lancaster: Centre for Science Studies, Lancaster University. Retrieved from http:// www.lancaster.ac.uk/fass/resources/sociology-online-papers/papers/lawmatter-ing.pdf, accessed 9 November 2015.

MacCannell, Dean. 1976. The Tourist: A New Theory of the Leisure Class. Berkeley, CA: University of California Press.

Mauss, Marcel. 1925 [2011]. The Gift. Forms and Functions of Exchange in Archaic Societies. Mansfield Centre, CT: Martino Publishing.

Mol, Annemarie. 1999. "Ontological Politics. A Word and Some Questions." In Actor Network Theory and after, edited by John Law and John Hassard, 74-89. Oxford: Blackwell Publishing.

Mol, Annemarie. 2002. The Body Multiple: Ontology in Medical Practice. Durham, NC and London: Duke University Press.

Ren, Carina, Annette Pritchard, and Nigel Morgan. 2010. "Constructing Tourism Research: A Critical Inquiry." Annals of Tourism Research 37 (4): 885-904.

Smith, Valene L., ed. 1977. Hosts and Guests. The Anthropology of Tourism. Philadelphia, PA: University of Pennsylvania Press.

Tribe, John, Graham Dann, and Tazim Jamal. 2015. "Paradigms in Tourism Research: A Trialogue." Tourism Recreation Research 40 (1): 28-47.

Turner, Louis, and John Ash, 1975. The Golden Hordes: International Tourism and the Pleasure Periphery. London: Constable.

United Nations World Tourism Organization (UNWTO). 2015. Tourism Highlights. 2015 Edition. Retrieved from http://www.e-unwto.org/doi/ pdf/10.18111/9789284416899, accessed 9 November 2015.

Urry, John. 1990. The Tourist Gaze: Leisure and Travel in Contemporary Societies. London: Sage.

Zuiderent-Jerak, Teun, and Stans van Egmond. 2015. "Ineffable Cultures or Material Devices: What Valuation Studies can Learn from the Disappearance of Ensured Solidarity in a Health Care Market." Valuation Studies 3 (1): 45-73. 
Carina Ren is Associate Professor in the Tourism Research Unit at Aalborg University Copenhagen. Her main research interests are tourism encounters and tourism innovations, which she explores through branding initiatives and mega-events and in destination development. She is a co-editor of Actor-Network Theory and Tourism. Ordering, Materiality and Multiplicity (Routledge, 2012) and Tourism Encounters and Controversies. Ontological Politics of Tourism Development (Ashgate, 2015). She has published her work in journals such as Annals of Tourism Research, Science Studies, and Ethnologia Europaea.

Morten Krogh Petersen is Assistant Professor in the TechnoAnthropology Research Group at Aalborg University Copenhagen. Utilizing modes of analysis from the field of science and technology studies (STS), especially material semiotics, he studies innovation and design as distributed, heterogeneous and collaborative achievements. He has published in journals such as Science Studies, Ethnologia Europaea and Techné: Research in Philosophy and Technology.

Dianne Dredge is Professor in Tourism Policy and Destination Development in the Tourism Research Unit, Aalborg University Copenhagen. Her main areas of interest are critical tourism policy and planning, regional development, tourism and the collaborative economy, and tourism higher education. She chairs the Tourism Education Futures Initiative (TEFI) and is co-editor of five books including Stories of Practice: Tourism Policy and Planning (Ashgate) and the Routledge Handbook of Tourism and Hospitality Education. 